\title{
Analysis of landslide damage caused by the 2008 Wenchuan earthquake using strong motion data: A case study in the Beichuan county town*
}

\author{
Xiuying Wang ${ }^{1, *}$ Gaozhong $\mathrm{Nie}^{2}$ and Song Wang ${ }^{3}$ \\ ${ }^{1}$ Institute of Crustal Dynamics, China Earthquake Administration, Beijing 100085, China \\ ${ }^{2}$ Institute of Geology, China Earthquake Administration, Beijing 100029, China \\ ${ }^{3}$ China Earthquake Networks Center, Beijing 100045, China
}

\begin{abstract}
The county town of Beichuan county, China, experienced catastrophic destruction due to landslides induce by the 2008 Wenchuan earthquake. In consideration of the special location of the county town, this paper selected the landslides induced in the town as representative of large-scale near-rupture landslides, and quantitatively analyzed why the landslide damage was so destructive in the town by using strong motion data obtained from the Wenchuan earthquake in the Longmenshan area. Three methods were employed to estimate the landslide damage using strong motion data. (1) Peak ground accelerations (PGAs) on the hanging wall were used to evaluate the PGAs on the landslide sites in the town. The evaluated average PGAs were all greater than $1 \mathrm{~g}$, indicating that the ground motion intensity was very strong during the earthquake. (2) Acceleration time histories, from another station with similar geological conditions to the town, were used to evaluate the critical acceleration changing range, and the estimated values showed the geological conditions were very susceptible to earthquakes. (3) Acceleration time histories, from two stations on the hanging and foot walls of the rupture, and near the town, were used to calculate the Newmark displacements, and all the evaluated displacements indicated that landslides were very likely. The results show that the slopes, susceptible to earthquakes in the Beichuan county town, were easily triggered under such strong ground-motion intensity and developed into large-scale catastrophic events.
\end{abstract}

Key words: Wenchuan earthquake; landslide; strong motion; evaluation; critical acceleration CLC number: P315.9 Document code: A

\section{Introduction}

The May 12, 2008 Wenchuan earthquake caused a significant number of landslides, and affected an area of over $2 \times 10^{5} \mathrm{~km}^{2}$, of which over $1 \times 10^{5} \mathrm{~km}^{2}$ was seriously stricken (Liu, 2008). Beichuan county was one of the most seriously affected regions. According to the survey after the earthquake, there were 564 landslides in Beichuan county, 21 of which were triggered in the county town (Jiang et al., 2009). For example, the Wangjiayan

\footnotetext{
* Received 18 February 2012; accepted in revised form 20 June 2012; published 10 August 2012.

† Corresponding author.e-mail: xiuyw@sohu.com

(C) The Seismological Society of China, Institute of Geophysics, China Earthquake Administration, and Springer-Verlag Berlin Heidelberg 2012
}

landslide buried more than 1600 people in the county town (Yin, 2008; Xu and Huang, 2008), and the Tangjiashan landslide blocked the river, which made it the most dangerous landslide induced by the earthquake.

Since the earthquake, numerous landslide studies in Beichuan county have been undertaken. These studies include the distribution rule and the triggering mechanisms of earthquake-induced large-scale landslides (Wang et al., 2008; Huang and Li, 2008; Xu, 2009). However, most of these studies were qualitative, and lacked the support of quantitative calculation. Therefore, this paper presents a quantitative analysis using the strong motion data obtained from the Wenchuan earthquake.

The Beichuan county town suffered the most de- 
structive landslides compared to those in Beichuan county and other counties in the earthquake-hit area. As a result of the extensive surface damage, all the instruments deployed in the county town were destroyed. Fortunately, many sets of strong motion data were obtained from the earthquake rupture in the Longmenshan area, which provides the opportunity to analyze the earthquake hazards using the ground motion data (Li et al., 2008). Therefore, we used this dataset to study the landslides that occurred in the county town, and quantitatively analyzed why the landslide damage was so serious.

Here, we calculated the strong motion intensity in the landslide sites of the county town and the probable displacements caused by the strong motion using the acceleration time histories obtained from the Wenchuan earthquake. The results show that the county town experienced very strong ground motion during the earthquake, which was strong enough to trigger large-scale landslides.

\section{Geological background and dataset}

The Wenchuan earthquake occurred on the central Yingxiu-Beichuan fault of the Longmenshan fault zone, which belongs to the transitional zone between the Qinghai-Xizang plateau and Sichuan basin. This region is characterized by complex geological structures, topography, and hydro-geological conditions (Xu et al., 2008), which resulted in a considerable number of secondary geological disasters as a result of the earthquake.

Beichuan county, located in the north-central part of the Wenchuan earthquake rupture, belongs to the Mianyang city of the Sichuan province. The land surface in Beichuan county is deeply incised and the local relief can exceed $1000 \mathrm{~m}$. The county town is located in a northeast-trending valley that developed in fissile Cambrian sandstone and slate, as well as Devonian dolomitic limestone that weathers easily.

The two landslides mentioned above, the Wangjiayan landslide and the Tangjiashan landslide, were located in the town and were close to the earthquake rupture. Therefore, we chose these two landslides as typical large-scale near-rupture landslide examples to carry out this study. Table 1 summarizes some data on the two most disastrous landslides.

Since no strong motion data was obtained from the county town, we tried to make use of the acceleration record data obtained in the Longmenshan area to carry out our work. Of these records, there are 23 groups from the hanging wall of the rupture. The distribution of these stations and their relationship to the rupture and the county town are shown in Figure 1.

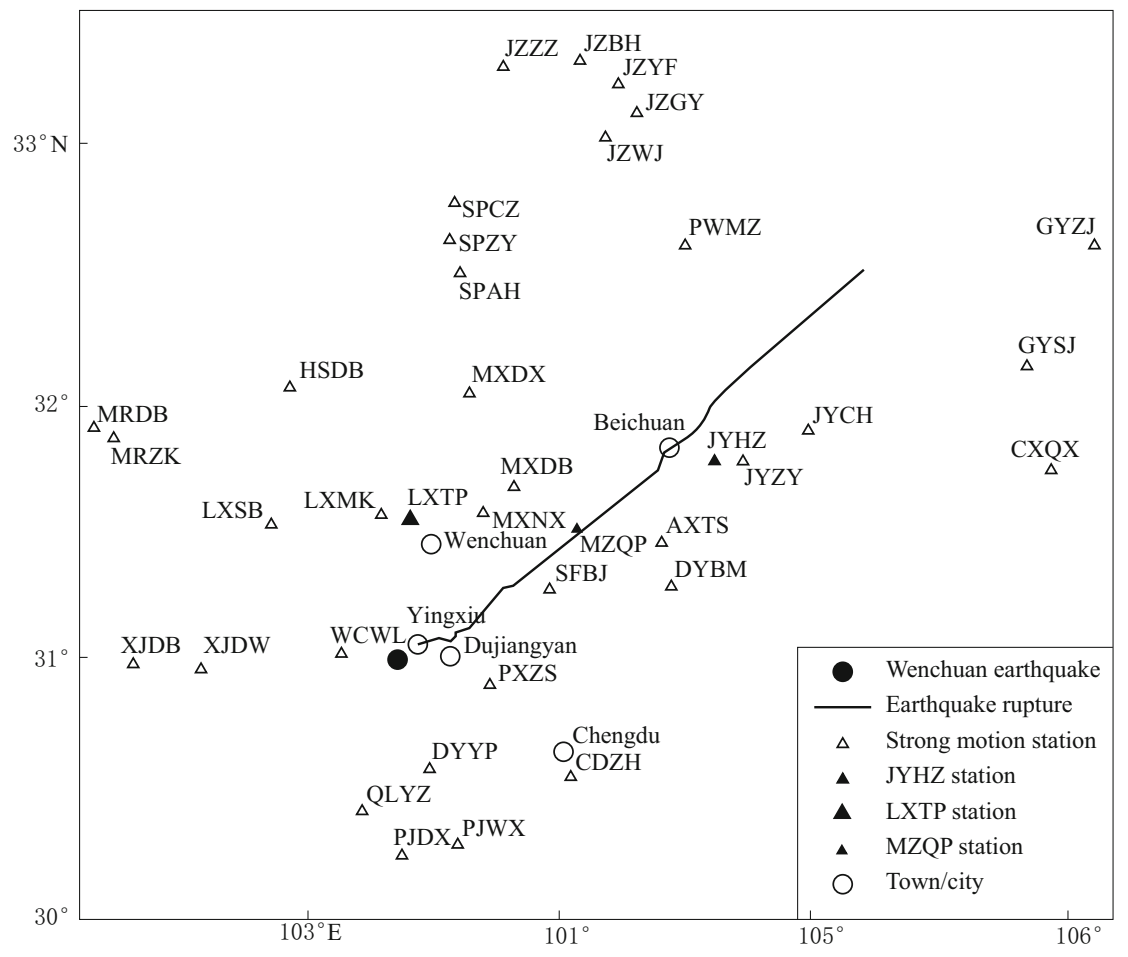

Figure 1 Distribution of the strong motion stations in the Longmenshan area. 
Table 1 Summary information on the Wangjiayan and Tangjiashan landslides triggered in the Beichuan county town

\begin{tabular}{cccccc}
\hline Landslide & Distance to rupture $/ \mathrm{km}$ & Landslide slippage $/ \mathrm{m}$ & Landslide volume $/ \mathrm{m}^{3}$ & Death toll & Source \\
\hline Wangjiayan & 0.5 & 550 & $1.0 \times 10^{6}$ & 1600 & Wang et al. (2009a) \\
Tangjiashan & 2.3 & 900 & $2.0 \times 10^{7}$ & 100 & Hu et al. (2009) \\
\hline
\end{tabular}

In Figure 1, the triangles indicate the stations where the strong motion data was recorded. The distribution of these stations and their relation to the earthquake rupture can be seen. The solid triangles are those stations which were selected for special calculation. The LXTP station was selected owning to its similar geological conditions to the county town. Slope parameters can be assessed using data with similar geological background. While the MZQP and JYHZ stations were selected because they were closest to the county town, but they were on the hanging and foot walls, respectively. Their calculation results can be compared as representative data. Therefore, the rich strong-motion dataset obtained in the Longmenshan area allows us to quantitatively assess the landslide hazards in the county town, even though there were no data for the study point. We used this dataset to analyze the two significant landslides mentioned above.

\section{Landslide hazard evaluations in the Beichuan county town}

\subsection{Peak ground acceleration evaluation of the landslide sites}

All the investigation carried out after the earthquake showed that earthquake damage was significantly greater on the hanging wall than that on the foot wall (Xu and Li, 2010). Studies also showed that the attenuation of the ground motion on the hanging wall was slower than it was on the foot wall (Yu et al., 2008).
The landslide sites, located in the county town, were on the hanging wall of the earthquake rupture, and located very close to the rupture. Therefore, estimated peak ground acceleration (PGA) values from the attenuation law based on all the dataset of this earthquake were not suitable to the special location of these landslides. To estimate the PGAs correctly, we used the data obtained from the hanging wall in the Longmenshan area to determine the attenuation-fitting formula in three directions. As shown in Figure 1, only the data located northwest of the rupture within the hanging wall, with the rupture distances less than $150 \mathrm{~km}$, were used to build the fitting laws. The fitting results were as follows:

$$
\begin{aligned}
\lg \mathrm{PGA}_{\mathrm{EW}} & =-1.39 \lg \left(D_{\mathrm{f}}+15.8\right)+1.95, \\
\sigma & =0.22, \quad r=-0.84, \\
\lg \mathrm{PGA}_{\mathrm{NS}} & =-1.29 \lg \left(D_{\mathrm{f}}+16.2\right)+1.76, \\
\sigma & =0.26, \quad r=-0.77, \\
\lg \mathrm{PGA}_{\mathrm{UD}} & =-1.52 \lg \left(D_{\mathrm{f}}+13.7\right)+2.05, \\
\sigma & =0.26, \quad r=-0.83,
\end{aligned}
$$

where $D_{\mathrm{f}}$ indicates the distance to earthquake rupture.

Using the rupture distances given in Table 1, we calculated the PGAs in the three directions for the two large-scale landslides, the Wangjiayan and Tangjiashan. The estimated average PGA values of the two landslide sites in three directions are given in Table 2 .

Table 2 PGA evaluation results for Wangjiayan and Tangjiashan landslides

\begin{tabular}{cccc}
\hline Landslide & $\begin{array}{c}\text { PGA }_{\text {EW }} \text { and its } \\
\text { estimation interval/g }\end{array}$ & $\begin{array}{c}\text { PGA }_{\text {NS }} \text { and its } \\
\text { estimation interval/g }\end{array}$ & $\begin{array}{c}\text { PGA }_{\text {UD }} \text { and its } \\
\text { estimation interval/g }\end{array}$ \\
\hline Wangjiayan & $1.8(1.1,3.1)$ & $1.5(0.83,2.8)$ & $2.0(1.1,3.6)$ \\
Tangjiashan & $1.6(0.96,2.6)$ & $1.3(0.73,2.4)$ & $1.7(0.91,3.0)$ \\
\hline
\end{tabular}

Analyzing the results given in Table 2, we determined that the estimated PGAs, in the three directions of the two landslide sites, were greater than $1 \mathrm{~g}$. Considering the fitting error within one standard deviation above and below the estimated average value, the lower limits of the estimated values were also near to or greater than $1 \mathrm{~g}$. These were in accordance with the hypothesized PGA data of more than $1 \mathrm{~g}$, or even $2 \mathrm{~g}-3 \mathrm{~g}$, from previous studies of the near-rupture landslides (Xu et al., 2008; Yin, 2009; Wang et al., 2009c), which were assumed from the observed damages. Moreover, the Wangjiayan and Tangjiashan landslides, as with many near-rupture large-scale landslides, had the characteristic of being propelled away from the top of 
the slope (Xu, 2009). For a large landslide mass to be propelled away so quickly in a very short time, an acceleration greater than $1 \mathrm{~g}$ is required to overcome gravity. This suggested that over $1 \mathrm{~g}$ PGA evaluations were credible.

The evaluated vertical PGAs of the two sites were both greater than their corresponding horizontal values. Studies showed that the vertical motion was very strong near the earthquake rupture, but the attenuation rate was rapid with increasing distance from the rupture (Yu et al., 2008). Studies of strong earthquakes also showed that landslide disasters near the earthquakerupture were invariably very serious (Jibson et al., 2006; Liao, 2000; Huang and Li, 2008). It was evident that there was a strong attenuation relationship between the near-rupture large-scale landslide hazards and the vertical strong motion, which demonstrated, to some extent, that although horizontal motion had a leading role in the landslide triggering process, as many researchers believed, the vertical motion must not be neglected, as it may intensify landslide hazards. This was also evident in our regional-scale studies (Wang et al., 2009b). Therefore, the vertical strong motion must be taken into consideration when near-rupture geological disasters are evaluated. Moreover, we can analyze the estimated result from the perspective of the forces acting on a block located on a sloping surface (slope block), as shown in Figure 2 .
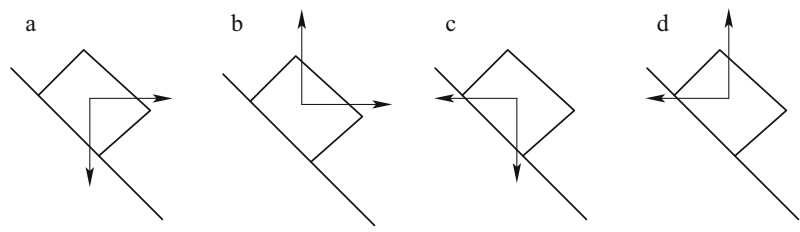

Figure 2 Cases of horizontal and vertical accelerations acting on a block resting on a slopping surface (slope block).

As for the cases c and d shown in Figure 2, the horizontal acceleration produces force inwards and upwards of the slope, which inhibits sliding. Whereas, in the cases a and b, horizontal acceleration produces force outwards and downwards of the slope. This is favorable for slippage. In the following section we analyze the vertical accelerations action under these two cases.

When the vertical acceleration acts downwards (case a), components of inwards and downwards of the slope are produced. The inwards component will enhance the pressure on the slope block, which leads to an increase in frictional force between the block and the sloping surface, while the downwards component will promote sliding. If the horizontal acceleration is large enough, the increased friction will be overcome and failure will occur.

When the vertical acceleration acts upwards (case b), components of outwards and upwards of the slope will be produced. Pressure and friction caused by the weight of the block will decrease. However, the upwards component will require a significant horizontal acceleration to be overcome in order to induce sliding. Therefore, in the near-rupture region where vertical accelerations are typically quite large and where the horizontal and vertical accelerations act on the slope at the same time, the horizontal acceleration must be large enough to propel the slope block away from the slope in order to cause landsliding. This analysis is in accordance with the estimated values given in Table 2 , where both the vertical and horizontal evaluated values are large. Under these conditions, when the combination of the vertical and horizontal accelerations acts on the slope, very large forces will be exerted on the slope block, which can lead to large-scale devastating landslides.

The damaging outcome of this earthquake and the above analyses, both show that the vertical component of the earthquake motion plays an important role in the near-rupture large-scale landslides. We will carry out more in-depth studies on this subject in future.

\subsection{Slope critical acceleration evaluation}

As discussed in section 2, the surface layer is weak due to weathering in the region around the county town. Therefore, the region is susceptible to landsliding in response to earthquakes or other triggering factors. To analyze the landslide hazards quantitatively, we tried to evaluate the changing range of critical acceleration under such geological conditions using the strong motion data obtained from another station in the regions that are characterized by similar geological conditions.

Critical acceleration, a parameter in acceleration format, represents the ability of a slope to remain stable when the slopes are subjected to an earthquake. A higher critical acceleration value means the slope can undergo greater ground motion intensity without landslide failure, while a lower critical acceleration signifies a slope that fails easily to earthquake motion (Wang et al., 2011a, b).

To evaluate the probable critical acceleration range, we use the acceleration-time history data and landslide information beside the observation point where the data was recorded to deduce this parameter (Wang et al., 2009b). Alternatively, we can obtain a 
possible value of this parameter by comparing the PGAs with the landslide hazards directly (Wang et al., 2010). Since we want to analyze the landslides in a quantitative way, we choose the first way to carry out the evaluation process.

The first step was to select a group of records, where the geological conditions were similar to the study site and induced landslide information was available. From the geological map in Figure 1, we established the Taoping station in Lixian county (LXTP) (bigger solid triangle) that had the same emergence stratum as the Beichuan county town, and the geological conditions in these two sites were similar. Therefore, we chose strong motion data from this station to carry out the evaluation process.

Since the horizontal motion played the major role in sliding, as shown in previous studies (Arias, 1970; Wilson and Keefer, 1985) and in section 3.1 of this study, two horizontal recordings were used to calculate the Newmark displacements by applying different critical accelerations. The average displacement value of the two horizontal components at the same critical acceleration point were used, and a group of Newmark displacements versus their corresponding critical accelerations were obtained (Figure 3 ).

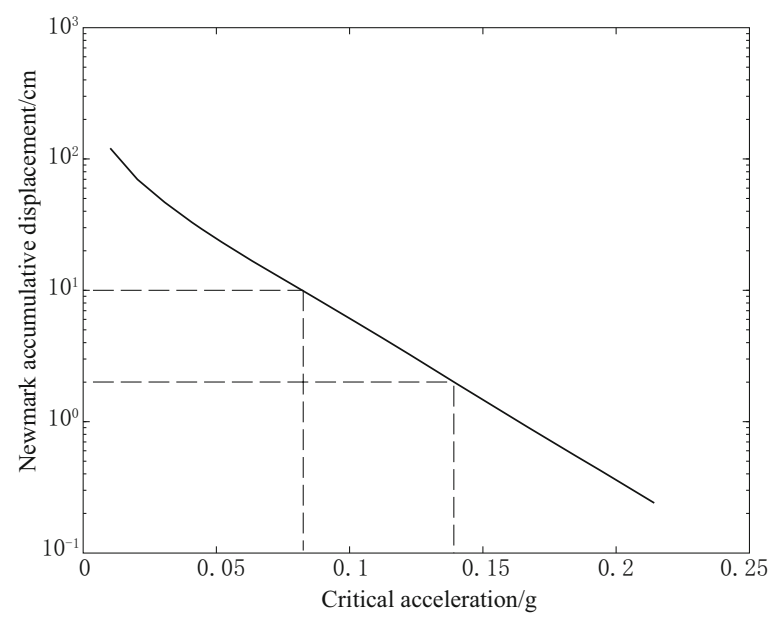

Figure 3 Newmark displacement vs. critical acceleration.

According to the surveyed data, there were largeto small-scale landslides near the LXTP station (Wang et al., 2009b). This indicated that the strong motion near the LXTP station was enough to trigger large-scale landslides. Wilson and Keefer (1985) stated that the critical displacement, a displacement over which elasticity of the slope material was lost and permanent dis- placement was produced, i.e., landslides occurred, could be selected as $2 \mathrm{~cm}$ for brittle slopes and $10 \mathrm{~cm}$ for coherent large-scale landslides. Therefore, we used these values and obtained the corresponding critical accelerations of $0.14 \mathrm{~g}$ and $0.08 \mathrm{~g}$ for $2 \mathrm{~cm}$ and $10 \mathrm{~cm}$, respectively (Figure 3).

Furthermore, our analysis using the regional scale data showed that landslide disasters were very serious when PGAs exceeded $0.2 \mathrm{~g}$ (Wang et al., 2010), which showed that the critical acceleration on a regional scale could not be greater than $0.2 \mathrm{~g}$ (Wang et al., 2009b). Therefore, we also used this value as a critical acceleration in the following section's calculation as a comparison.

Our results showed that the critical acceleration range was about $0.08 \mathrm{~g}$ to $0.14 \mathrm{~g}$, with the maximum less than $0.2 \mathrm{~g}$, for the geological conditions of the Beichuan county town region. The critical acceleration range of $0.08 \mathrm{~g}$ to $0.14 \mathrm{~g}$ indicated that the geological conditions in the town were susceptible to earthquakes, and that landslides were easily triggered.

\subsection{Newmark displacement evaluation}

Having determined the critical acceleration, the next step was to select an acceleration time history to calculate the probable Newmark displacement. To make a comparison, we chose two groups of records near the town, but those that were located on both the hanging wall and foot wall of the rupture. These stations are the Qingping station (MZQP) on the hanging wall and the Hanzeng station (JYHZ) on the foot wall (small solid triangles in Figure 1). Although the MZQP station is located on the hanging wall like the county town, its geological conditions are quite different from the town. While the JYHZ station has similar geological conditions to the town, it is located on the footwall and is at a greater distance from the rupture. Therefore, it is reasonable to use both sets of data.

The Newmark displacements, calculated from the critical accelerations given in section 3.2 using the acceleration time-histories of the two selected stations, are shown in Table 3. See Wang et al. (2009b) for a detailed discussion of the calculation process.

From the results given in Table 3, we determined that if the strong motion intensity in the town was the same as that of the MZQP station, large-scale landslides would be triggered under any of the critical accelerations. This is because all the displacements, even under the most disadvantageous slope condition ( $0.2 \mathrm{~g}$ critical acceleration) were large enough. Even if the strong motion intensity was as great as that of the JYHZ sta- 
tion, landslides would also have been triggered because all the displacements were greater than the critical displacement of $2 \mathrm{~cm}$, a typical value for slopes made of weak materials. The landslides might, however, be smaller than those under the conditions of the MZQP station. Yet, when the rupture distance and the foot wall location were taken into consideration, we determined that the ground motion in the town must be stronger than that in the JYHZ station, and therefore landslide disasters would be more serious than those of the JYHZ station.

Table 3 Newmark displacement calculation results

\begin{tabular}{cccc}
\hline \multirow{2}{*}{ Station } & \multicolumn{3}{c}{$\begin{array}{c}\text { Newmark displacement for different } \\
\text { critical acceleration/cm }\end{array}$} \\
\cline { 2 - 4 } & $0.08 \mathrm{~g}$ & $0.14 \mathrm{~g}$ & $0.2 \mathrm{~g}$ \\
\hline MZQP & 60.3 & 20.2 & 7.7 \\
JYHZ & 18.4 & 6.3 & 2.3 \\
\hline
\end{tabular}

These results show that the Newmark displacements in the county town were large enough to trigger large-scale landslides under any of the critical accelerations mentioned above, even under the most unfavorable conditions. However, it must be noted that the calculated Newmark displacements were much smaller than those of the real landslide slippage, for example, the $550 \mathrm{~m}$ of the Wangjiayan landslide, given in Table 1. We think there are two reasons to explain this. First, the critical acceleration was kept at a constant value throughout the acceleration time history calculations, while in a real case when the slope is subjected to an earthquake, the mechanical properties of the soil might change and its anti-shearing ability should be weakened. This would result in the critical acceleration becoming progressively smaller during the vibration. Second, the horizontal time history was adopted when the Newmark displacements were calculated and the vertical component was neglected, which might play an important role in the near rupture landslide calculations mentioned above; therefore, the vertical strong motion must be taken into consideration in future model studies.

As a result, the Newmark displacement, whether calculated from the time history, or evaluated in any other way, should not be taken as the real landslide slippage. However, when the regional characteristics are considered and a suitable judging criterion is adopted, the Newmark displacement, in a quantitative manner, is also a very good index to evaluate landslide risks on a regional scale or for certain landslide sites.

\section{Conclusions}

The Beichuan county town suffered the most devastating landslides of all the areas affected by the Wenchuan earthquake, and no strong motion data were obtained from the town. Consequently, this study evaluated the probable PGAs of the town using the data from the hanging wall of the Wenchuan earthquake in the Longmenshan area, and evaluated the critical acceleration range and corresponding Newmark displacements. Some conclusions are as follows:

1) The average evaluated PGAs of the two landslide sites in the county town were all greater than $1 \mathrm{~g}$. Even if the one standard deviation formula fitting error was considered, the minimum evaluated values were near to, or greater than $1 \mathrm{~g}$, which is in accordance with the results from other studies. The vertical strong motion likely played an important role in large-scale nearrupture landslides, which must be considered in future evaluation models.

2) Acceleration time histories, from another station with the same geological conditions as the Beichuan county town, were used to evaluate the critical acceleration range. The results suggested ground accelerations of $0.08 \mathrm{~g}$ to $0.14 \mathrm{~g}$, which showed that slopes in this condition were susceptible to earthquakes, and therefore, landslides, were easily triggered.

3) Acceleration time histories, from two stations located on the hanging and foot walls near the rupture, were selected to calculate the Newmark displacements. The results showed that landslides might be triggered even if the ground motion, located on the footwall at a far distance from the rupture, was used. The Newmark displacement, combined with a suitable judgment criterion, was a good index for landslide risk evaluations, but it cannot be used for real landslide slippage.

Through these analyses, we have concluded that the destructive near-rupture landslides of the Beichuan county town were triggered because of the extremely strong ground motion, in particular, the vertical ground motion, under disadvantageous slope conditions.

We evaluated and analyzed the landslide hazards, at the locations where the damage was very serious, but strong motion data were absent, by using data obtained from other stations during the Wenchuan earthquake. Furthermore, we can use the methods shown in this paper to evaluate parameters in other geological conditions in the Longmenshan area, which might be suitable as a decision rule or judgement criterion in future project applications. 
Acknowledgements This research was supported by the National Science and Technology Supporting Item of China (No. 2012BAK15B06) and the project from Institute of Crustal Dynamics, China Earthquake Administration (No. ZDJ2010-28).

\section{References}

Arias A (1970). A measure of earthquake Intensity. In: Hansen R J ed. Seismic Design for Nuclear Power Plants. MIT Press, Massachusetts, Cambridge, 438-483.

Hu X W, Huang R Q, Shi Y B, Lu X P, Zhu H Y and Wang X R (2009). Analysis of blocking river mechanism of Tangjiashan landslide and dam breaking mode of its barrier dam. Chinese Journal of Rock Mechanics and Engineering 28(1): 181-189 (in Chinese with English abstract).

Huang R Q and Li W L (2008). Research on development and distribution rules of geohazards induced by Wenchuan earthquake on 12th May 2008. Chinese Journal of Rock Mechanics and Engineering 27(12): 2 5852592.

Jiang J Y, Song Y and Gu H B (2009). Analysis of development of geologic hazard in $M_{\mathrm{S}} 8.0$ Wenchuan earthquake. Journal of Institute of Disaster-Prevention Science and Technology 11(1): 43-47 (in Chinese with English abstract).

Jibson R W, Harp E L, William S and Keefer D K (2006). Large rock avalanches triggered by the M7.9 Denali fault, Alaska earthquake of 3 November 2002. Engineering Geology 83: 144-160.

Li X J, Zhou Z H, Yu H Y, Wen R Z, Lu D W, Huang M, Zhou Y N and Cui J W (2008). Strong motion observations and recordings from the great Wenchuan earthquake. Earthquake Engineering and Engineering Vibration 7(3): 235-246.

Liao Hsuan-Wu (2000). Landslides Triggered by ChiChi Earthquake. [MS Dissertation]. Taiwan University, Taipei, 99 (in Chinese with English abstract).

Liu C Z (2008). Disasters induced by Wenchuan earthquake, Sichuan, China, and geo-environmental safety. Geological Bulletin of China 27(11): 1 907-1 912 (in Chinese with English abstract).

Wang G L, Zhang J H and Liu H S (2009a). Investigation and preliminary analysis of geologic disasters in Beichuan county induced by Wenchuan earthquake. The Chinese Journal of Geological Hazard and Control 20(3): 47-51 (in Chinese with English abstract).

Wang X Y, Nie G Z and Wang D W (2009b). Analysis of landslide induced by Wenchuan earthquake by strong motion records. Chinese Journal of Rock Mechanics and Engineering 28(11): 2 369-2 376 (in Chinese with English abstract).

Wang X Y, Nie G Z and Ma M J (2011a). Evaluation model of landslide hazards induced by the 2008 Wenchuan earthquake using strong motion data. Earthquake Science 24(3): 311-319.

Wang X Y, Nie G Z and Wang D W (2010). Research on relationship between landslides and peak ground accelerations induced by Wenchuan earthquake. Chinese Journal of Rock Mechanics and Engineering 29(1): 82-89 (in Chinese with English abstract).

Wang X Y, Nie G Z and Wang S (2011b). Ground motion acceleration criterion for judging landslide induced by the 2008 Wenchuan earthquake. Acta Seismologica Sinica 33(1): 82-90 (in Chinese with English abstract).

Wang Y S, Luo Y H, Ji F, Huo J J, Wu J F and Xu H B (2008). Analysis of the controlling factors on geo-hazards in mountainous epicenter zones of the Wenchuan earthquake. Journal of Engineering Geology 16(6): 759-763 (in Chinese with English abstract).

Wang Y S, Xu H B, Luo Y H and Wu J F (2009c). Study of formation conditions and toss motion program of high landslides induced by earthquake. Chinese Journal of Rock Mechanics and Engineering 28(11): 2 360-2 368 (in Chinese with English abstract).

Wilson R C and Keefer D K (1985). Predicting areal limits of earthquake-induced landsliding. In: Ziony J I ed. Evaluating Earthquake Hazards in the Los Angeles Region --An Earth-Science Perspective. U.S. Geological Survey Professional 16. Paper 1 360, 317-345.

$\mathrm{Xu}$ Q (2009). Main types and characteristics of the geohazards triggered by the Wenchuan earthquake. Journal of Geological Hazards and Environment Preservation 20(2): 86-93 (in Chinese with English abstract).

Xu Q and Huang R Q (2008). Kinetics characteristics of large landslides triggered by May 12th Wenchuan earthquake. Journal of Engineering Geology 16(6): 721-729 (in Chinese with English abstract).

Xu Q and Li W L (2010). Distribution of large-scale landslides induced by the Wenchuan earthquake. Journal of Engineering Geology 18(6): 818-826 (in Chinese with English abstract).

Xu X W, Wen X Z and Ye J Q (2008). The $M_{\mathrm{S}} 8.0$ Wenchuan earthquake surface ruptures and its seismogenic structure. Seismology and Geology 30(3): 597-629 (in Chinese with English abstract).

Yin Y P (2008). Researches on the geo-hazards triggered by Wenchuan earthquake, Sichuan. Journal of Engineering Geology 16(4): 433-444 (in Chinese with English abstract).

Yin Y P (2009). Rapid and long run-out features of landslides triggered by the Wenchuan earthquake. Journal of Engineering Geology 17(2): 153-166 (in Chinese with English abstract).

Yu H Y, Wang D and Yang Y Q (2008). The preliminary analysis of strong motion characteristics from the $M_{\mathrm{S}}$ 8.0 Wenchuan earthquake, China. Technology for Earthquake Disaster Prevention 3(4): 321-336 (in Chinese with English abstract). 